\title{
Presence of $\mathrm{N}$-acyl and acetoxy derivatives of putrescine and cadaverine in the human gut
}

\author{
K E Murray, K J Shaw, R F Adams, P L Conway
}

\begin{abstract}
$\mathrm{N}$-acyl and acetoxy derivatives of putrescine and cadaverine have been found in the faeces of children and in cultures of isolates of gut bacteria. The evidence was accumulated from two dimensional, thin layer chromatography, field desorption mass spectrometry, and accurate mass measurement of the DANS derivatives of the amines. The acetoxy compounds of putrescine and cadaverine have not previously been reported

(Gut 1993; 34: 489-493)
\end{abstract}

Monoacetylcadaverine (N-acetyl-1,5-diaminopentane) and monopropionylcadaverine (Npropionyl-1,5-diaminopentane) have been shown to occur frequently in the urine of schizophrenic patients, of psychotic or mentally defective patients, and of mentally normal patients in hospital.' These same compounds have since been reported in human blood, where their levels were found to be significantly higher in schizophrenic patients than in normal subjects. ${ }^{23}$ Acetylputrescine ( $\mathrm{N}$-acetyl-1,4-diaminobutane), and to a lesser degree acetylcadaverine, along with other acetyl polyamines, occur in increased amounts in the urine of cancer patients compared with normal subjects. ${ }^{4}$

Many methods have been developed for analysing these compounds as biochemical markers to aid diagnosis and to monitor the regression of cancerous tumours after chemotherapy. ${ }^{5}$ In a recent study in this laboratory, tentative identifications were made of mono-Nacyl-diamines in the faeces of 35 of 44 infants with gastroenteritis, by field desorption mass spectrometry (FDMS) of the fluorescamine derivatives. ${ }^{6}$ We present here evidence for the presence of $\mathrm{N}$-acyl- and acetoxy-putrescines and cadaverines in a variety of samples associated with the human gut, namely: faeces from children, caecal fluid, and spent culture fluid

TABLE I The presence of dansyl-diamine and related molecular ions in material recovered from thin layer chromatography separations followed by field desorption mass spectrometry

\begin{tabular}{|c|c|c|c|c|c|c|c|c|}
\hline \multirow[b]{2}{*}{ Source } & \multicolumn{3}{|c|}{$\begin{array}{l}\text { Acyldiamines } \\
(\mathrm{m} / \mathrm{z})\end{array}$} & \multicolumn{3}{|c|}{$\begin{array}{l}\text { Diamines } \\
(\mathrm{m} / \mathrm{z})\end{array}$} & \multicolumn{2}{|c|}{$\begin{array}{l}\text { Acetoxydiamines } \\
(\mathrm{m} / \mathrm{z})\end{array}$} \\
\hline & 363 & 377 & 391 & 540 & 554 & 568 & 612 & 626 \\
\hline $\begin{array}{l}\text { A } \dagger \text { Faeces } \\
\text { B Faeces } \\
\text { C Faeces } \\
\text { D Faeces } \\
\text { E } \neq \text { Faeces } \\
\text { F\ Caecal fluid }\end{array}$ & $\begin{array}{l}++ \\
++\end{array}$ & $\begin{array}{l}++^{\star} \\
+ \\
++\end{array}$ & ++ & + & $\begin{array}{l}+ \\
+++ \\
+++ \\
++ \\
++\end{array}$ & $\begin{array}{l}+++ \\
+ \\
+ \\
+++ \\
+++ \\
+++\end{array}$ & $\begin{array}{l}++ \\
+ \\
+++\end{array}$ & +++ \\
\hline
\end{tabular}

* Semiquantitative assessment of the relative amounts was made from the intensity of the spots where possible and from the ion intensity in the FD spectra.

Relative abundance of ion: ++++ very large,+++ large,++ medium,+ small tSubjects A-D were infants aged 6-12 months, admitted to hospital with salmonellosis. $¥$ Subject $E$ was a hyperactive child, aged 6 years.

$\S$ Subject $F$ was a child aged 3 years with suspected infant botulism. from isolates of gut micro-organisms. Identification of the compounds was obtained in $1-10 \mu \mathrm{g}$ samples by thin layer chromatography (TLC), FDMS, and accurate mass measurement of the molecular ions of the 1-dimethylaminonaphthalene-5-sulphonyl- (DANS) derivatives of the amines concerned.

\section{Methods}

SUBJECTS AND SOURCES OF SPECIMENS

An initial source of faecal specimens was a group of five infants admitted to hospital with salmonellosis (Table I). The specimens were taken before antibiotic treatment was begun. A group of 13 children (reported previously ${ }^{6}$ ) provided a second source of faecal specimens. These children had been admitted to hospital for reasons unrelated to gastric problems and were not receiving any drug treatment. Spent culture fluids of faecal smears, single cell isolates from duodenal biopsy specimens, and a specimen of caecal fluid obtained at necropsy from a child with suspected infant botulism were the nonfaecal samples used. The cultures were incubated anaerobically for four days at $37^{\circ} \mathrm{C}$ in prereduced supplemented brain-heart infusion broth.

\section{MICROBIOLOGY}

When faecal samples were inadequate for processing directly to determine the concentration of amines, faecal smears were taken with sterile swabs. The tips of the swabs were transferred to $5 \mathrm{ml}$ aliquots of Stuart's transport medium and individual smears and medium were used to inoculate $100 \mathrm{ml}$ prereduced supplemented brain-heart infusion broth (SBHI) containing haemin $(5 \mu \mathrm{g} / \mathrm{ml})$, vitamin $\mathrm{K}(10 \mu \mathrm{g} / \mathrm{ml})$, and yeast extract $(0 \cdot 5 \%)$. The SBHI was prereduced with resazurin and cysteine. ' The inoculated medium was incubated anaerobically in 5\% hydrogen and $95 \%$ nitrogen for four days at $37^{\circ} \mathrm{C}$. After incubation, the bacterial cells were separated by centrifugation at $10000 \mathrm{~g}$ and the spent medium was processed to concentrate any diamines as described below.

Duodenal biopsy and aspirate samples were collected by endoscopy, placed immediately in Stuart's transport medium, and inserted in an anaerobic atmosphere inside a Biobag (Marion Scientific Industries, USA). Microbiological culturing was carried out within four hours of sampling. Necropsy samples from the ascending colon of one subject suspected of suffering from infant botulism were transferred immediately after collection to an anaerobic atmosphere inside a Biobag and stored overnight at $4^{\circ} \mathrm{C}$. All 
TABLE II Presence of diamine-dansyl and related molecular ions in field desorption spectra of DANS amines in faeces and microbial cultures

\begin{tabular}{|c|c|c|c|c|c|c|c|c|c|c|c|}
\hline \multicolumn{4}{|c|}{$\begin{array}{l}\text { Acyldiamines } \\
(\mathrm{m} / \mathrm{z})\end{array}$} & \multicolumn{3}{|c|}{$\begin{array}{l}\text { Diamines } \\
(\mathrm{m} / \mathrm{z})\end{array}$} & \multicolumn{5}{|c|}{$\begin{array}{l}\text { Acetoxydiamines } \\
(\mathrm{m} / \mathrm{z})\end{array}$} \\
\hline 363 & 377 & 391 & 405 & 540 & 554 & 568 & 584 & 598 & 612 & 626 & 640 \\
\hline
\end{tabular}

Subject/source:

Faeces - infants*

$\begin{array}{lllllll}\text { A } & \mathrm{F} & + & \text { Hospital } & ++\ddagger & ++ & + \\ \mathrm{B} & \mathrm{M} & 7 & \text { Hospital } & + & ++++ & +++\mathrm{T}\end{array}$

$\begin{array}{llll}\text { B } & M & 7 & \text { Hospital } \\ \text { C } & M & 4 & \text { Hospital } \\ \text { D } & \text { F } & & \end{array}$

$\begin{array}{llll}\mathrm{D} & \mathrm{F} & 12 & \text { Hospital } \\ \mathrm{E} & \mathrm{M} & 10 & \text { Hospital }\end{array}$

$\begin{array}{llll}\text { E } & \text { M } & 10 & \text { Hospital } \\ \text { F } & \text { M } & 12 & \text { Home }\end{array}$

$\begin{array}{llrl}\text { F } & \text { M } & 12 & \text { Home } \\ \text { G } & \text { F } & 9 & \text { Home }\end{array}$

$\begin{array}{llll}\mathrm{G} & \mathrm{F} & 9 & \text { Home } \\ \mathrm{H} & \mathrm{F} & 8 & \text { Home }\end{array}$

I $\mathrm{F} 6$ Home

J M 12 Home

$\mathrm{K}$ F 4 Home

$\mathrm{M}$ F 11 Home

Culturest

Cultures $\dagger$ Faecal smear

Faecal smear

Faecal smear

Isolate from gut

Isolate from gut
Isolate from gut

Isolate from gut
Isolate from gut

Isolate from gut



$+$

++
++
+++

++
++
++

$+$

$++$

$+++$

+
++

$+$

$+$

$+$

$+$

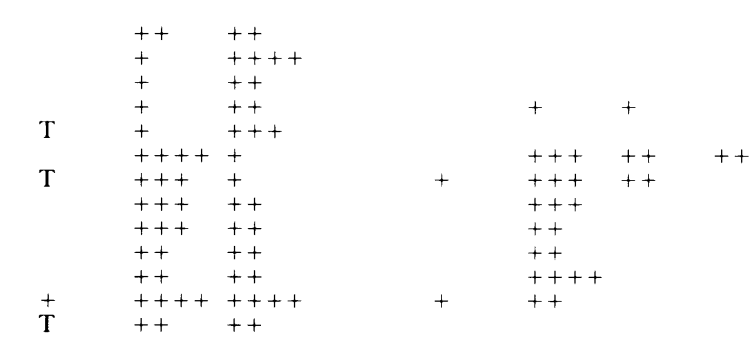

* Subjects listed with sex and age in months. All subjects were healthy and were studied previously (reference 6 ). * Subjects listed with sex and age in months. All subjects were healthy and were studied previously (reference 6 ).
+ Faecal smears were from hyperactive children $(1,2)$ and a child with suspected infant botulism $(3)$. Isolates of single microbial strains were from gut biopsy tissue of two children $(4,5,6$ and 7,8$)$

$\ddagger$ Assessment of relative abundance of ions was as described in Table I.

$\mathrm{T}=$ trace.

samples were serially diluted in 10 fold steps in prereduced phosphate buffered saline $(0.01 \mathrm{M}$, $\mathrm{pH} 7 \cdot 2)$. Aliquots $(100 \mu \mathrm{l})$ of the dilutions were inoculated into prereduced SBHI containing 2\% agar. Tubes containing $10 \mathrm{ml}$ sterile SBHI agar
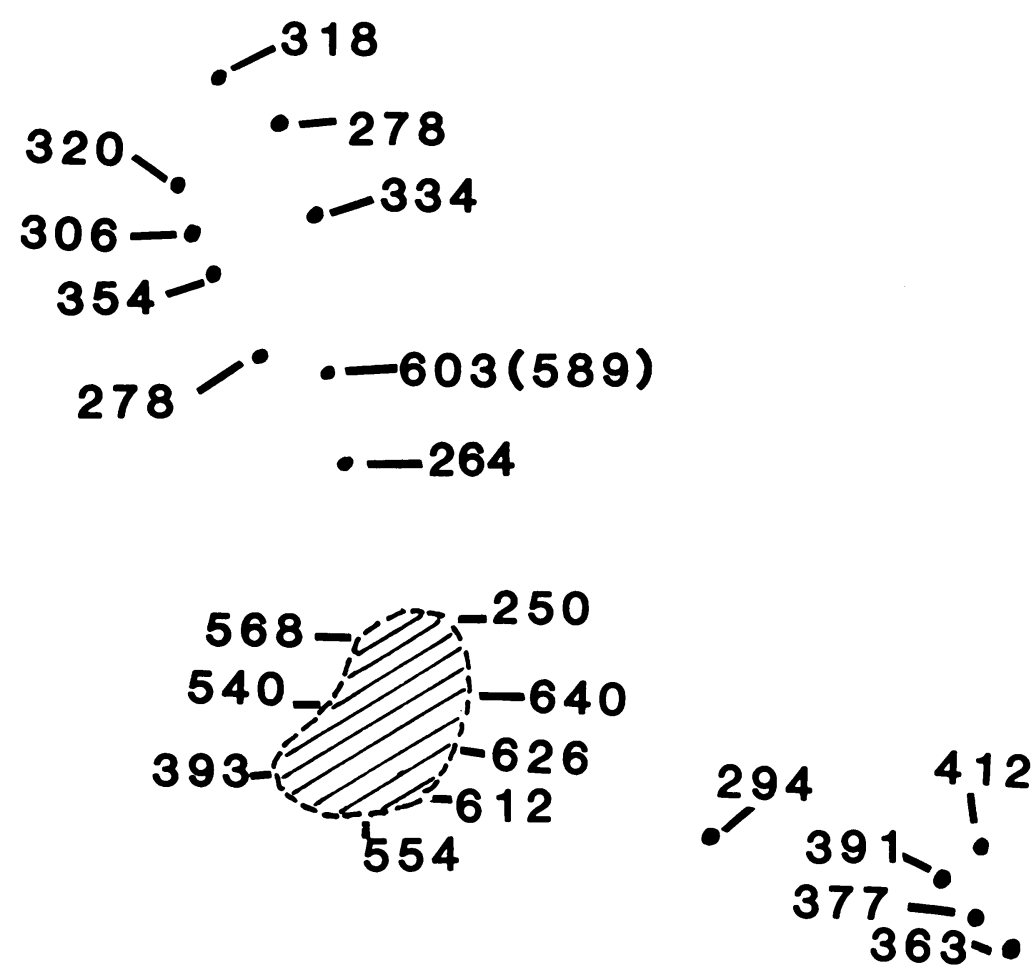

Figure 1: Composite molecular ion-thin layer chromatography (TLC) map of 1-dimethylaminonaphthalene-5-sulphonyl (DANS)-amines (free) recovered by ion exchange from the faeces of children. Identity of molecular ions $(\mathrm{m} / \mathrm{z})$, upper left to origin. Centre of spots shown. 318 - piperidine, 278 - dimethylamine (from reagent in reaction), $334-$

5-aminopentanal (from cadaverine), 320-isopentylamine (mixed 2-and 3-methylbutylamines (from isoleucine and leucine respectively), 306 - isobutylamine (from valine), 354 -

2-phenylethylamine, 278 -ethylamine, 603 - p-tyramine, 589 - p-hydroxvbenzylamine likely (present only when p-tyramine is large) 264-methylamine, 250-ammonia, 568 -cadaverine, 540 -1,3-diaminopropane, 393 -tryptamine, 554-putrescine, 612-2-acetoxyputrescine, 626 -2-(or 3)-acetoxycadaverine, 640-2-(or 3)-propionyloxycadaverine, 294 - ethanolamine, 412 - acetyltyramine (present when tyramine is large), 391 - mono- $N$-propionylcadaverine, 377 - mono- $N$-acetylcadaverine, 363 - mono- $N$-acetylputrescine. Experimental conditions: 2-I) TLC solvent combination of Seiler and Weichmann." were steamed, equilibrated to $50^{\circ} \mathrm{C}$ in a water bath, and then spun to distribute the culture medium uniformly on their walls before they were inoculated. After incubation at $37^{\circ} \mathrm{C}$ for five days, dominant colonies were subcultured and purified by spirally inoculating prespun tubes of prereduced SBHI agar.' The spiral tubes were further incubated for five days at $37^{\circ} \mathrm{C}$. All manipulations of dilutions and SBHI agar tubes were performed under a stream of carbon dioxide gas. Purified cultures were finally grown in prereduced SBHI broth with $20 \%$ glycerol and stored at $-20^{\circ} \mathrm{C}$ in the culture medium. Before the cultures were frozen, spent culture fluid was prepared by inoculation of $0 \cdot 1 \%$ in SBHI broth with $1 \%$ glucose. After three days' incubation at $37^{\circ} \mathrm{C}$, the cultures were centrifuged at $10000 \mathrm{~g}$ to remove the bacterial cells.

RECOVERY AND DERIVATISATION OF AMINES

The recovery of amines from samples by ion exchange chromatography and their derivatisation was as previously described. ${ }^{6}$ The FDMS method had a limit of detection of about 100 $\mathrm{nmol} / \mathrm{g}$ faeces, based on a sample size of $1 \mathrm{~g}$, one tenth of the sample applied to the FD emitter and an MS sensitivity of about $10 \mathrm{nmol}$ in the ion source. The limit of detection of the TLC methodology was previously estimated to be $0 \cdot 2$ nmol. ${ }^{\circ}$

TLC

Two dimensional TLC (2-D TLC) was based on the methodology of Seiler and Weichmann. ${ }^{*}$ The solvents of choice were: first direction, ethyl acetate:cyclohexane $(3: 2 \mathrm{v} / \mathrm{v}) ;$ and second direction, benzene:triethylamine (5:1). A second solvent combination found to separate diamines and acetoxydiamines was: first direction, as above; second direction, chloroform:isopropanol 




Figure 2: Field desorption molecular ion spectra of 1-dimethylaminonapthalene-5-sulphonyl $(D A N S)$-amines in the bis-DANS region. From $($ Table II $)(A)$ infant $K,(B)$ infant $F,(C)$ culture $6,(D)$ culture 8 .

Figure 3: Single development is on the left $(A)$ and $2 D$ thin layer chromatography (TLC) on the right $(B)$. From material recovered after $T L C$, field desorption mass spectrometry was used to establish the following sequence of $D A N S$ derivatives $(A): A$, ammonia; $B$, putrescine; $C$ cadaverine; $D$,

acetoxydiamines $(\mathrm{m} / \mathrm{z} 626$, $612)$, and $E, 5$ aminopentanal.

Experimental conditions: first solvent ethyl acetate: cyclohexane $(3: 2 \mathrm{v} / \mathrm{v})$, second solvent in $2 D-T L C$ chloroform: isopropanol $(25: 1 v / v)$.
FDMS was used as previously described for the molecular ion analysis of the dansylated amines without their prior separation. ${ }^{6}$ It was also used to establish the identities of the DANS-amine derivatives separated by 2-D TLC, after solvent recovery from the fluorescent spots.

Desorption electron ionisation mass spectrometry (DEI-MS) provided a follow up technique of obtaining data for the precise mass measurement of the DANS-amines. This was possible because of the relatively intense molecular ions recorded for the DANS-amines under DEI-MS conditions and the stability of the EI ion beam. The mass spectrometer was a Varian-MAT 311A (Varian-MAT, Bremen, Germany) with an EI/FD source. This allowed a rapid changeover from FD to DEI conditions by retraction of the FD field emitter a few millimetres to just clear the electron beam which was substituted for the ionising field. The sample (1-10 $\mu \mathrm{g})$ was loaded onto the field emitter and introduced into the mass spectrometer electron beam in a manner similar to that used for FD. Reference materials were admitted from a separate heated inlet. The source temperature was $90^{\circ} \mathrm{C}$ and the resolution of the mass spectrometer was 5000. Peak matching of the molecular ions and reference masses was manual.

\section{Results}

FDMS DATA OF DANS DERIVATIVES OF DIAMINES RECOVERED AFTER TLC

Table I presents evidence for the presence of putrescine (bis-DANS-1,4-diaminobutane, $\mathrm{m} / \mathrm{z}$ 554 ) in five specimens and cadaverine (bisDANS-1,5-diaminopentane, $\mathrm{m} / \mathrm{z}$ 568) in six specimens. A series of related molecular ions $(\mathrm{m} / \mathrm{z} \mathrm{363}, 377$, and 391) were detected in one or more of four of the specimens. Other molecular ions $(\mathrm{m} / \mathrm{z} 612,626)$ were present in three samples. Table II summarises the ions present in samples from healthy infants and the spent microbial fluids. These ions were each recorded as the sole or most prominent component in material recovered from the fluorescent spots on the 2D-TLC plates. A composite TLC map of amines in children's faeces (Fig 1) was constructed from data gathered from the TLC-




FDMS examination of specimens listed in Tables I and II.

Since earlier work had shown that the DANSamines were quite stable under FDMS conditions ${ }^{6}$ and produced only the molecular group of ions in their spectrum, it was more informative and simpler to scan the DANS-amines without prior separation by chromatographic methods. In the mass ranges used, covering $\mathrm{m} / \mathrm{z}$ 300-650, background noise was extremely low, so that all the ions showing were molecular ions. Figure 2 shows four FDMS scans in the bis-DANSdiamine region $(\mathrm{m} / \mathrm{z} 530-650)$. Even though the TLC-m/z map was informative (Fig 1 ), however, all specimens were still submitted to 2-D TLC, and fluorescent spots were examined by FDMS for confirmatory purposes only when considered necessary. Table III summarises the data relating to the precise mass measurements of compounds associated with the DANS molecular ions $(\mathrm{m} / \mathrm{z} 363,377,391,612$, and 626$)$ obtained under DEI-MS conditions. It is suggested by their molecular size that the compounds $(\mathrm{m} / \mathrm{z} 612,626)$ contain two DANS groups. Figure 3 is a TLC plate of the DANS total amines in the faeces of a 4 year old girl, and shows the separation from ammonia of putrescine, cadaverine, and their acetoxyderivatives (2-acetoxy-bis-DANS-1,4-diaminobutane, $\mathrm{m} / \mathrm{z}$ 612, and 2-(or 3)-acetoxy-bisDANS-1,5-diaminopentane, $\mathrm{m} / \mathrm{z} 626$ ).

\section{Discussion}

The evidence for the presence of $\mathrm{N}$-acetyl and acetoxy derivatives of putrescine and cadaverine in the faeces of children is summarised below.

(1) The occurrence of the molecular ions of bis-DANS derivatives of putrescine $(\mathrm{m} / \mathrm{z} 554)$ and cadaverine $(\mathrm{m} / \mathrm{z} 568)$ in FDMS scans of the total amines was frequently associated with the presence of other ions, namely $\mathrm{m} / \mathrm{z} 363$ with putrescine and $\mathrm{m} / \mathrm{z} 377$ and 391 with cadaverine. This was clear when one or the other diamine was much more abundant, as shown by examples in Tables I and II.

Similarly, it was suggestive that the ion $\mathrm{m} / \mathrm{z}$ 612 was associated with the presence of putrescine $(\mathrm{m} / \mathrm{z} 554)$ and $\mathrm{m} / \mathrm{z} 626$ with the presence of cadaverine $(\mathrm{m} / \mathrm{z} 568)$, as shown in Tables I and II and Figure 2(B).

(2) In a previous study of amines in the faeces of children with gastroenteritis, ${ }^{6}$ again using FDMS but with fluorescamine derivatives, we observed members of an homologous series $(\mathrm{m} / \mathrm{z}$ $390,404,418,432$ ) in a high proportion of the specimens. These were provisionally identified as $\mathrm{N}$-acylated (acetyl, propionyl, butyryl) deriva- tives of putrescine and cadaverine, $\mathrm{m} / \mathrm{z} 390$ and $\mathrm{m} / \mathrm{z} 404$ representing $\mathrm{N}$-acetylputrescine and $\mathrm{N}$ acetylcadaverine respectively. Whenever there were substantial concentrations of putrescine or cadaverine, they were usually accompanied by $\mathrm{N}$-acetylputrescine or $\mathrm{N}$-acetylcadaverine.

(3) Precise mass measurement of the DANSderivatives of the acetyl and acetoxy compounds provided strong confirmatory evidence for their identification (Table III). This was made clearer when the large DANS contribution to the derived molecular formulas was subtracted. Subtracting the elements of one DANS group $\left(\mathrm{C}_{12} \mathrm{H}_{11} \mathrm{O}_{2} \mathrm{NS}\right.$, 233) followed by those of one acetyl group $\left(\mathrm{C}_{2} \mathrm{H}_{2} \mathrm{O}, 42\right)$ or two DANS groups and one acetyl group, gave formulas corresponding to putrescine (88), cadaverine (102), hydroxyputrescine (104), and hydroxycadaverine (118) (Table III). TLC and MS evidence below indicated that $\mathrm{m} / \mathrm{z} 391$ was propionylcadaverine and the mass of a propionyl group $\left(\mathrm{C}_{3} \mathrm{H}_{4} \mathrm{O}, 56\right)$ was therefore subtracted. Further subtraction of the amine groups and oxygen left saturated hydrocarbon residues $-\left(\mathrm{CH}_{2}\right)_{4}-$ and $-\left(\mathrm{CH}_{2}\right)_{5}-$ which are clearly carbon saturated.

(4) An authentic specimen of mono-Npropionylcadaverine (bis-DANS derivative $\mathrm{m} / \mathrm{z}$ 391 ), dansylated and chromatographed by $2 \mathrm{D}$ TLC under the conditions given in Figure 1, gave an intense fluorescence spot identical to that shown. Authentic specimens of other mono-Nacyldiamines were not available.

(5) The two compounds (DANS derivatives $\mathrm{m} / \mathrm{z} 612$ and $\mathrm{m} / \mathrm{z} 626$ ), presumed on evidence thus far to be 2-acetoxyputrescine and 2-(or 3)acetoxycadaverine, were shown by 2D-TLC to be very close to the bis-DANS-putrescine and bis-DANS-cadaverine, all being embedded in the unresolved area with an excess of ammonia (Fig 1). These compounds were resolved with a polar solvent mixture (chloroform:isopropanol, 25:1) to give the results shown in Figure 3(A) for single development and in Figure 3(B) for 2DTLC. From material recovered from the plate after multiple $(20 \times)$ single development, FDMS established the sequence of DANS derivatives in Figure 3(A): A, ammonia; B, putrescine; C, cadaverine, $\mathrm{D}$, acetoxydiamines $(\mathrm{m} / \mathrm{z} 626,612)$ and E, 5-aminopentanal. By the use of the same polar solvent as the second solvent (first solvent as in Fig 1) it was then possible to name the resolved spots as in Figure 3(B). The finding that the two bis-DANS-acetoxydiamines travelled slightly ahead of the diamines in a polar solvent was consistent with their having a slightly more polar structure.

The occurrence of mono- $\mathrm{N}$-acyldiamines in faeces would not be surprising in view of their

TABLE III Accurate mass measurement and derived elemental compositions for DANS acyldiamines and acetoxydiamines by desorption electron ionisation mass spectrometry

\begin{tabular}{|c|c|c|c|c|c|c|c|c|}
\hline $\begin{array}{l}\text { Dansyl } \\
(\mathrm{m} / \mathrm{z})\end{array}$ & $\begin{array}{l}\text { Reference } \\
\text { mass }\end{array}$ & $\begin{array}{l}\text { Measured } \\
\text { mass }\end{array}$ & $\begin{array}{l}\text { Calculated } \\
\text { mass }\end{array}$ & $\begin{array}{l}\text { Difference } \\
\text { mass, mmu }\end{array}$ & $\begin{array}{l}\text { Molecular } \\
\text { formula }\end{array}$ & $\begin{array}{l}\text { Formula less } \\
\text { dansyl }\end{array}$ & Less acetyl & \\
\hline 363 & $\begin{array}{l}\text { Pentacosanone } \\
366\end{array}$ & 363.1627 & 363.1617 & $1 \cdot 0$ & $\mathrm{C}_{18} \mathrm{H}_{25} \mathrm{O}_{3} \mathrm{~N}_{3} \mathrm{~S}$ & $\mathrm{C}_{6} \mathrm{H}_{1+} \mathrm{ON}_{2}$ & $\mathrm{C}_{4} \mathrm{H}_{12} \mathrm{~N}_{2}$ & (88) \\
\hline $\begin{array}{l}377 \\
391 \\
612 \\
626\end{array}$ & $\begin{array}{l}\text { PFK } 369 \\
\text { PFK } 381 \\
\text { Fomblin } 617 \\
\text { Fomblin } 617\end{array}$ & $\begin{array}{l}377.1743 \\
391.1920 \\
612.2035 \\
626.2238\end{array}$ & $\begin{array}{l}377.1773 \\
391.1930 \\
612.2077 \\
626.2233\end{array}$ & $\begin{array}{l}3 \cdot 0 \\
1 \cdot 0 \\
4 \cdot 2 \\
0 \cdot 5\end{array}$ & $\begin{array}{l}\mathrm{C}_{19} \mathrm{H}_{27} \mathrm{O}_{3} \mathrm{~N}_{3} \mathrm{~S} \\
\mathrm{C}_{20} \mathrm{H}_{29} \mathrm{O}_{3} \mathrm{~N}_{3} \mathrm{~S} \\
\mathrm{C}_{30} \mathrm{H}_{36} \mathrm{O}_{6} \mathrm{~N}_{4} \mathrm{~S}_{2} \\
\mathrm{C}_{31} \mathrm{H}_{38} \mathrm{O}_{6} \mathrm{~N}_{4} \mathrm{~S}_{2}\end{array}$ & $\begin{array}{l}\mathrm{C}_{7} \mathrm{H}_{16} \mathrm{ON}_{2} \\
\mathrm{C}_{8} \mathrm{H}_{18} \mathrm{ON}_{2} \\
\mathrm{C}_{6} \mathrm{H}_{14} \mathrm{O}_{2} \mathrm{~N}_{2} \\
\mathrm{C}_{7} \mathrm{H}_{16} \mathrm{O}_{2} \mathrm{~N}_{2}\end{array}$ & $\begin{array}{l}\mathrm{C}_{5} \mathrm{H}_{1+} \mathrm{N}_{2} \\
\mathrm{C}_{5} \mathrm{H}_{1+} \mathrm{N}_{2}^{\star} \\
\mathrm{C}_{4} \mathrm{H}_{12} \mathrm{ONN}_{2} \\
\mathrm{C}_{5} \mathrm{H}_{1+} \mathrm{ON}_{4}\end{array}$ & $\begin{array}{l}(102) \\
(102) \\
(104) \\
(118)\end{array}$ \\
\hline
\end{tabular}

*Earlier thin layer chromatography and mass spectrometry evidence indicated that $\mathrm{m} / \mathrm{z} 391$ dansyl is propionyl cadaverine and the propionyl mass has therefore been subtracted. 
reported occurrence in urine and blood. ${ }^{12}$ Although putrescine and cadaverine were the major diamines in faeces (Tables I and II), the acetoxy compounds $(612,626)$ can in some cases also occur in comparable amounts (Table II). It is noteworthy that all infants who showed relatively large amounts of acetoxyputrescine (Table II subjects F-K) were healthy and attending the same baby clinic. The acetoxydiamines were found almost exclusively in children at home, despite the fact that the infants in hospital were admitted for reasons unrelated to gastric problems and were not receiving any drug treatment. The children in hospital were long term patients, however, and the difference could possibly be explained by variations in diet and the resulting changes in gut microflora.

Another possible minor acyloxy compound was propionyloxycadaverine (2-(or 3)-propionyloxy-1,5-diaminopentane, bis-DANS derivatives $\mathrm{m} / \mathrm{z} 640$ ) in one subject, $\mathrm{F}$. There were also clear traces of $\mathrm{m} / \mathrm{z} 540$ and $\mathrm{m} / \mathrm{z} 598$ compounds indicating the presence of 1,3-diaminopropane and its derivatives.

The hydroxydiamines themselves were certainly not prominent components, but there was evidence of the presence of small amounts of $\mathrm{m} / \mathrm{z} 584$, corresponding to hydroxycadaverine (2-(or 3)-hydroxy-bis-DANS-1,5-diaminopentane). This was present in three of the microbial cultures (Table II and Figs 2(C) and (D)). The ion representing hydroxyputrescine (2-hydroxybis-DANS-1,4-diaminobutane, $\mathrm{m} / \mathrm{z} 570$ ) would normally be swamped by the intense isotopic ions of bis-DANS-cadaverine, $\mathrm{m} / \mathrm{z} 568$, but in Figure 2(B) where bis-DANS-cadaverine was low there was a small increase in ion $\mathrm{m} / \mathrm{z} 570$, suggesting the presence of a small amount of bisDANS-hydroxyputrescine.

2-Hydroxyputrescine has been reported to be produced by Pseudomonas acidovorans, and several other strains of Pseudomonas and other unspecified bacteria. ${ }^{9}$ It has also been isolated from bovine brain. ${ }^{10} \mathrm{~A}$ study with ${ }^{14} \mathrm{C}$-labelled putrescine ${ }^{11}$ showed that 2-hydroxyputrescine derives from putrescine presumably by direct hydroxylation. There are no reports of a similar hydroxylation pathway for cadaverine, but based on the behaviour of putrescine, such a pathway could be expected.

Putrescine and cadaverine are derived from ornithine and lysine by the action of their respective decarboxylases. ${ }^{12}$ Ornithine, however, is not present in food proteins, or only in traces, but is derived primarily from arginine by the loss of the elements of urea. ${ }^{13}$ Arginine and lysine, both abundant food protein constituents, would be expected to be available to the gut microflora from the dietary residue of a large intake of foods high in these amino acids - for example fish, meat, and eggs. ${ }^{1+}$

$\mathrm{N}$-acyldiamines have been reported to occur in urine and blood. ${ }^{\prime 2}$ Perry et al,' studying schizophrenic in patients, suggested that the high levels of urinary acetyldiamines could have been a reflection of a common insitutional gut microflora, hospital diet, or drug treatment. Dolezalova et $a l^{3}$ suggested that in schizophrenics, the raised blood level of $\mathrm{N}$-acylcada- verines is caused by increased activity of the $\mathrm{N}$-acylating enzymes. Both groups of workers were unable to specify where $\mathrm{N}$-acylation occurs in the body.

In this work it is seen that the cultured human gut micro-organisms obtained from the duodenum, caecum, and faeces produced putrescine, cadaverine, and their $\mathrm{N}$-acyl- and acyloxy-derivatives. This strongly suggests that the above compounds are products of the gut microflora, especially when supported by the isolation of 2-hydroxyputrescine (the parent of 2-acetoxyputrescine) from cultures of specific bacteria.

There seems to be no previous report of acetoxydiamines in the human body. Monoacetylputrescine has become prominent in cancer treatment as a marker compound to monitor cancer recession (along with other acetylated polyamines). ${ }^{5}$ It has been shown with mice that whereas putrescine accelerates cell proliferation in carcinomas, acetylputrescine has the reverse effect. ${ }^{15}$ If this effect were to be established in humans, this role of putrescine/ acetylputrescine could be of great significance.

Depending on the nature and amount of the dietary intake, the environment of the human gut has the capacity to generate a large pool of these important diamines and their derivatives. Any contemplated work, therefore, on diamines in any part of the human body should recognise this role of the gut microflora and have due regard to the dietary intake of their amino acid precursors.

1 Perry TL, Hansen S, MacDougall L. Identity and significance of some pink spots in schizophrenia and other conditions. Nature 1967; 214: 484-5.

2 Dolezalova $H$, Stepita-Klauco $M$, Kucera J, Uchimura $H$, Hirano M. Monoacylcadaverines in the blood of schizophrenic patients. Fournal of Chromatographic Biomedical Applications 1978; 146: 67-76.

3 Dolezalova H, Stepita-Klauco $M$, van der Velde $C D$, Cassone VM. Blood levels of cadaverine and its metabolites monoacetylcadaverine and monopropionylcadaverine in psychotic subgroups of schizophrenics. In: Frigerio A, ed. Recent developments in mass spectrometry and biochemical medicinal Vol 1. New York; Plenum, 1977: 297-319.

4 Abdel-Monem MM, Ohno K. Polyamine metabolism III: Urinary acetylpolyamines in human cancer. 7 Pharm Sci 1978; 67: 1671-3.

5 Kabra PM, Lee HK, Lubich WP, Marton LJ. Solid-phase extraction and determination of dansyl derivatives of unconjugated and acetylated polyamines by reversed-phase liquid chromatography: improved separation system for houid chromatography: improved separation system for polyamines in cerebrospinal fluid, u
of Chromatography 1986; 380: 19-32.

6 Murray KE, Adams RF, Earl JW, Shaw KJ. Studies of the free faecal amines of infants with gastroenteritis and of healthy infants. Gut 1986; 27: 1173-80

7 Holdeman LV, Cato EP, Moore WEC. Anaerobe laboratory manual, 4th ed. Blacksburg: VPI Polytechnical Institute, 1977.

8 Seiler $\dot{N}$, Weichmann $M$. TLC analysis of amines as their DANS-derivatives. In: Niederwieser Aed Progress in Thin Layer Chromatography Related Methods 1970; 1:95-144.

9 Tobari J, Tchen TT. Identification of $(+)$-hydroxyputrescine (1,4-diaminobutane-2-ol) from a Pseudomonas species. f Biol Chem 1971; 246: 1262-5.

10 Hasegawa T, Noto T, Nakao J, Kamimura H, Hashimoto H, Nakajima T. Identification of 2-hydroxyputrescine in mammakajima T. Identification of 2-hydroxyputrescine in mammalian brain

11 Tobari JJ, Tchen TT. Hydroxyputrescine: 1,4-diaminobutan2-ol. Methods Enzymol 1983;94:431-33.

12 Drasar BS, Hill MJ. Human intestinal microflora. London: Academic Press, 1974; 91 .

13 Drasar BS, Hill MJ. Human intestinal microflora. London: Academic Press, 1974; 94.

14 Scientific tables, 7th ed. Basle: JR Geigy, 1970; 516

15 Boggust WA, Al-Nakib T. Promotion and suppression of tumor growth and cell proliferation by acetylputrescine and putrescine and their oxidation products acetyl-GABA and GABA. International Research Communications System Medical Science 1986; 14: 174-5. 